\title{
Variations in body-weight of young women during the menstrual cycle
}

\author{
BY PATRICIA E. WATSON AND MARION F. ROBINSON \\ Department of Nutrition, School of Home Science, \\ University of Otago, Dunedin, New Zealand \\ (Received 7 September 1964-Accepted I7 November 1964)
}

Variations in body-weight during the menstrual cycle have been studied by a number of workers, with conflicting results. The existence of an increase in weight during the premenstrual phase in some or all of the subjects, followed by a decrease during or after menstruation, has been claimed by some (Thomas, I933; Okey \& Stewart, 1932-3; Sweeney, 1934; Thorn, Nelson \& Thorn, I938; Morton, 1950; Thomas, 1953; Fortin, Whittkower \& Kalz, r958; Bruce \& Russell, r962), but not confirmed by others (Klein \& Carey, I957; Chesley \& Hellman, 1957; Taggart, I962). Many of these studies are not comparable in respect to subjects, experimental procedures or analyses of results. Some of the subjects suffered from the symptoms of premenstrual tension (Morton, I950; Bickers \& Woods, 1951), some were patients in a psychiatric hospital (Bruce \& Russell, I962), and other groups were not homogeneous as regards occupations, living conditions or eating habits. The procedure for weighing was often not standardized (Robinson \& Watson, 1965), but three studies have been performed using metabolic balance techniques. Thorn et al. (1938) found a weight increase in four of six women in the premenstrual phase. Bruce \& Russell (I962) studied ten women for 4-9 weeks and found a weight increase in seven of the thirteen cycles, in the last 4-5 days before menstruation. Taggart (I962) studied in detail water and calorie balances in one subject and obtained no relationship between the menstrual cycle and the changes in body-weight, food intake and water balance.

The day-to-day fluctuations of body-weight in twenty-eight young women showed some consistency in their relation to the menstrual cycle (Robinson \& Watson, 1965). This association has now been followed further by considering the results for their forty-eight completed menstrual cycles. Analyses of the cycles together revealed an underlying rhythmic pattern of body-weight in time with the menstrual cycle. Successive cycles in any given subject, however, showed notable dissimilarities.

\section{EXPERIMENTAL}

A description of the subjects and of the procedure has been given in the accompanying paper (Robinson \& Watson, 1965). Twenty-eight young women (18-20 years) living and eating in the same residential hall were weighed in a standardized manner on rising each morning for 68 consecutive days.

A complete menstrual cycle was taken as beginning on day $\mathrm{x}$, the day on which the 
incidence of menstruation was reported when the subject was weighed in the morning, and ending with the next onset of menstruation. The time of ovulation was estimated from graphs of the basal morning oral temperature (Robinson \& Watson, 1965).

\section{RESULTS}

As with the analysis of the day-to-day variations, the trends in body-weight were eliminated and the analysis of the results was carried out on the corrected weights. The average initial and final weights were $61.47 \mathrm{~kg}$ (SD $5.72 \mathrm{~kg}$ ) and $61.35 \mathrm{~kg}$ (SD $5.7 \mathrm{rg}$ ), respectively. Within the 68 days of the experimental period, two subjects completed three cycles, sixteen completed two cycles, and ten subjects only one cycle, making a total of forty-eight cycles.

An average of three weighings was missed from each cycle. Half the missed weighings were for isolated days; the rest were accounted for by breaks of 2 days, except that on six occasions 3 consecutive days were missed and in two cycles there was a break of 4 days. Allowance was made for the missing weights by assuming that the weight had changed in a linear manner from the day preceding to the day following the missing weight or weights.

Table I contains the lengths of the completed cycles of all the subjects, together with the mean body-weight, the standard deviation and the coefficient of variation for each cycle calculated as by Khosla \& Billewicz (1964). The mean coefficient of variation was $0.65 \%$ (range $0.37-1 \cdot 02 \%$ ).

Since the lengths of the cycles varied from 15 to 42 days (mean 27 days) the cycles were compared as follows. The duration of menstruation was known (range 3-7 days, mean 5 days) and ovulation occurred 7-19 days (mean 13.5 days) before the onset of the next menses. Each cycle was divided into eight parts; the menstrual phase into two parts, the postmenstrual phase until the day of ovulation into a further two parts, and the postovulatory phase until the day immediately before the next menstruation into four parts. It was not possible to divide the menstrual phase into equal numbers of whole days if menstruation lasted for an odd number of days. The extra day was then added either to the first or to the second part at random. The same procedure was followed for the postmenstrual phase. Similarly, the postovulatory phase was divided as nearly as possible into four parts of equal length in whole days, extra days being distributed at random among the parts. Two cycles were considered to be anovular; the menstrual phase was divided into two parts and the time from the end of menstruation until the onset of the next menses was divided into six parts as above.

Changes in weight during the menstrual cycle calculated as the quotients of the deviations of the body-weights from the mean, divided by the standard deviation

Following the procedure of Danforth, Boyer \& Graff (1946), the quotient $d / \sigma$ was calculated for each of the eight parts of the cycle; $d$ is the average deviation of the body-weight for each part of the cycle from the mean body-weight for that cycle, and $\sigma$ is the standard deviation for the cycle. For each part, the results for the forty-eight 
cycles were averaged, taking account of sign. The values have been graphed in Fig. I with vertical lines indicating the range of $\pm 2 \mathrm{SE}$ (standard error).

A distinct pattern developed, showing an increase in $d / \sigma$ during the first half of

Table r. Mean weight with its standard deviation, and coefficient of variation for the completed menstrual cycles of twenty-eight young women

\begin{tabular}{|c|c|c|c|c|c|}
\hline $\begin{array}{c}\text { Subject } \\
\text { no. }\end{array}$ & $\begin{array}{l}\text { Height } \\
\text { (in.) }\end{array}$ & $\begin{array}{l}\text { Length of } \\
\text { cycle } \\
\text { (days) }\end{array}$ & $\begin{array}{c}\text { Mean } \\
\text { weight } \\
(\mathrm{kg})\end{array}$ & $\begin{array}{c}\text { SD } \\
(\mathrm{kg})\end{array}$ & $\begin{array}{l}\mathrm{CV}^{*} \\
(\%)\end{array}$ \\
\hline I & $68 \cdot 0$ & $\begin{array}{l}31 \\
26\end{array}$ & $\begin{array}{l}65 \cdot 54 \\
65.53\end{array}$ & $\begin{array}{l}0.35 \\
0.36\end{array}$ & $\begin{array}{l}0.53 \\
0.55\end{array}$ \\
\hline 2 & $67 \cdot 5$ & $\begin{array}{l}24 \\
28\end{array}$ & $\begin{array}{l}71 \cdot 73 \\
72 \cdot 04\end{array}$ & $\begin{array}{l}0.40 \\
0.41\end{array}$ & $\begin{array}{l}0.56 \\
0.57\end{array}$ \\
\hline 3 & $63 \cdot 2$ & 32 & $63 \cdot 54$ & 0.32 & 0.50 \\
\hline 4 & 63.3 & 29 & $52 \cdot 4 I$ & 0.30 & 0.57 \\
\hline 5 & 63.5 & $\begin{array}{l}32 \\
26\end{array}$ & $\begin{array}{l}57 \cdot 17 \\
57 \cdot 32\end{array}$ & $\begin{array}{l}0.27 \\
0.33\end{array}$ & $\begin{array}{l}0.47 \\
0.58\end{array}$ \\
\hline 6 & 69.0 & 29 & $58 \cdot 26$ & 0.34 & 0.58 \\
\hline 7 & $62 \cdot 0$ & $\begin{array}{l}24 \\
22\end{array}$ & $\begin{array}{l}59.27 \\
59.23\end{array}$ & $\begin{array}{l}0.26 \\
0.37\end{array}$ & $\begin{array}{l}0.44 \\
0.62\end{array}$ \\
\hline 8 & $66 \cdot 3$ & $\begin{array}{l}29 \\
31\end{array}$ & $\begin{array}{l}62 \cdot 92 \\
63 \cdot 09\end{array}$ & $\begin{array}{l}0.36 \\
0.36\end{array}$ & $\begin{array}{l}0.57 \\
0.57\end{array}$ \\
\hline 9 & $69 \cdot 5$ & $\begin{array}{l}24 \\
27\end{array}$ & $\begin{array}{l}60.37 \\
60.51\end{array}$ & $\begin{array}{l}0.47 \\
0.33\end{array}$ & $\begin{array}{l}0.78 \\
0.55\end{array}$ \\
\hline 10 & $62 \cdot 7$ & $\begin{array}{l}38 \\
15\end{array}$ & $\begin{array}{l}54 \cdot 19 \\
53 \cdot 91\end{array}$ & $\begin{array}{l}0.44 \\
0.55\end{array}$ & $\begin{array}{l}0.81 \\
1.02\end{array}$ \\
\hline I I & $66 \cdot 3$ & 30 & 63.68 & $0.6 \mathrm{I}$ & 0.96 \\
\hline I2 & 64 & $\begin{array}{l}18 \\
21\end{array}$ & $\begin{array}{l}63 \cdot 44 \\
63 \cdot 21\end{array}$ & $\begin{array}{l}0.45 \\
0.35\end{array}$ & $\begin{array}{l}0.71 \\
0.55\end{array}$ \\
\hline I3 & $64 \cdot 5$ & $\begin{array}{l}23 \\
35\end{array}$ & $\begin{array}{l}63 \cdot 45 \\
56 \cdot 53\end{array}$ & $\begin{array}{l}0.41 \\
0.50\end{array}$ & $\begin{array}{l}0.65 \\
0.89\end{array}$ \\
\hline 14 & 65 & $\begin{array}{l}27 \\
31\end{array}$ & $\begin{array}{l}64 \cdot 8 \mathrm{I} \\
64 \cdot 64\end{array}$ & $\begin{array}{l}0.29 \\
0.36\end{array}$ & $\begin{array}{l}0.45 \\
0.56\end{array}$ \\
\hline I6 & $67 \cdot 5$ & 42 & 55.05 & 0.32 & 0.58 \\
\hline r 7 & $65 \cdot 0$ & $\begin{array}{l}27 \\
26\end{array}$ & $\begin{array}{l}72 \cdot 59 \\
72 \cdot 51\end{array}$ & $\begin{array}{l}0.45 \\
0.63\end{array}$ & $\begin{array}{l}0.62 \\
0.84\end{array}$ \\
\hline$x 8$ & $68 \cdot 0$ & $\begin{array}{l}23 \\
28\end{array}$ & $\begin{array}{l}64 \cdot 25 \\
63 \cdot 74\end{array}$ & $\begin{array}{l}0.40 \\
0.52\end{array}$ & $\begin{array}{l}0.62 \\
0.82\end{array}$ \\
\hline I9 & $63 \cdot 2$ & 28 & $55^{\cdot 12}$ & 0.46 & 0.84 \\
\hline 20 & 64.5 & $\begin{array}{l}28 \\
26\end{array}$ & $\begin{array}{l}55 \cdot 27 \\
62 \cdot 36\end{array}$ & $\begin{array}{l}0.51 \\
0.43\end{array}$ & $\begin{array}{l}0.92 \\
0.69\end{array}$ \\
\hline & & 27 & $62 \cdot 32$ & 0.58 & 0.93 \\
\hline $2 I$ & $67 \cdot 7$ & $\begin{array}{l}21 \\
23\end{array}$ & $\begin{array}{l}59.98 \\
59 \cdot 78\end{array}$ & $\begin{array}{l}0.45 \\
0.37\end{array}$ & $\begin{array}{l}0.75 \\
0.62\end{array}$ \\
\hline & & 22 & 59.85 & $0.3 \mathrm{I}$ & 0.52 \\
\hline 22 & $62 \cdot 5$ & 33 & $75^{\circ} \cdot 20$ & 0.59 & 0.78 \\
\hline 23 & $69^{\circ} \circ$ & 31 & $62 \cdot 93$ & 0.37 & 0.59 \\
\hline 24 & $64 \cdot 8$ & $\begin{array}{l}25 \\
28\end{array}$ & $\begin{array}{l}5 I \cdot 49 \\
5 I \cdot 3 I\end{array}$ & $\begin{array}{l}0.36 \\
0.26\end{array}$ & $\begin{array}{l}0.70 \\
0.51\end{array}$ \\
\hline 25 & $63 \cdot 0$ & $\begin{array}{l}34 \\
25\end{array}$ & $\begin{array}{l}56 \cdot 18 \\
56 \cdot 22\end{array}$ & $\begin{array}{l}0.46 \\
0.29\end{array}$ & $\begin{array}{l}0.82 \\
0.52\end{array}$ \\
\hline 26 & $64 \cdot 5$ & 29 & $62 \cdot 15$ & 0.27 & 0.43 \\
\hline 28 & $62 \cdot 5$ & 23 & $58 \cdot 58$ & 0.30 & 0.51 \\
\hline 29 & $64 \cdot 5$ & $\begin{array}{l}21 \\
25\end{array}$ & $\begin{array}{l}57 \cdot 00 \\
57 \cdot 16\end{array}$ & $\begin{array}{l}0.27 \\
0.28\end{array}$ & $\begin{array}{l}0.47 \\
0.49\end{array}$ \\
\hline 30 & 66.7 & $\begin{array}{l}\text { I } \\
3 \text { I }\end{array}$ & $\begin{array}{l}66 \cdot 97 \\
66 \cdot 85\end{array}$ & $\begin{array}{l}0.54 \\
0.25\end{array}$ & $\begin{array}{l}0.81 \\
0.37\end{array}$ \\
\hline
\end{tabular}

Subjects 15 and 27 withdrew shortly after starting the study.

- Coefficient of variation $=\mathrm{sD} /$ mean $\times 100 \%$. 
menstruation which was followed by a pronounced loss in weight during the remainder of menstruation. Little change occurred in the postmenstrual phase until the time of ovulation. A peak appeared immediately after ovulation was assumed to have occurred, and then the quotient returned to the postmenstrual level again. Thereafter it rose steadily during the latter half of the postovulatory phase (the premenstrual phase). The observed differences from the mean were considered significant in the first, third, fourth, and sixth parts of the cycle, where the plotted band of $d / \sigma \pm 2$ SE lay completely above or below zero.

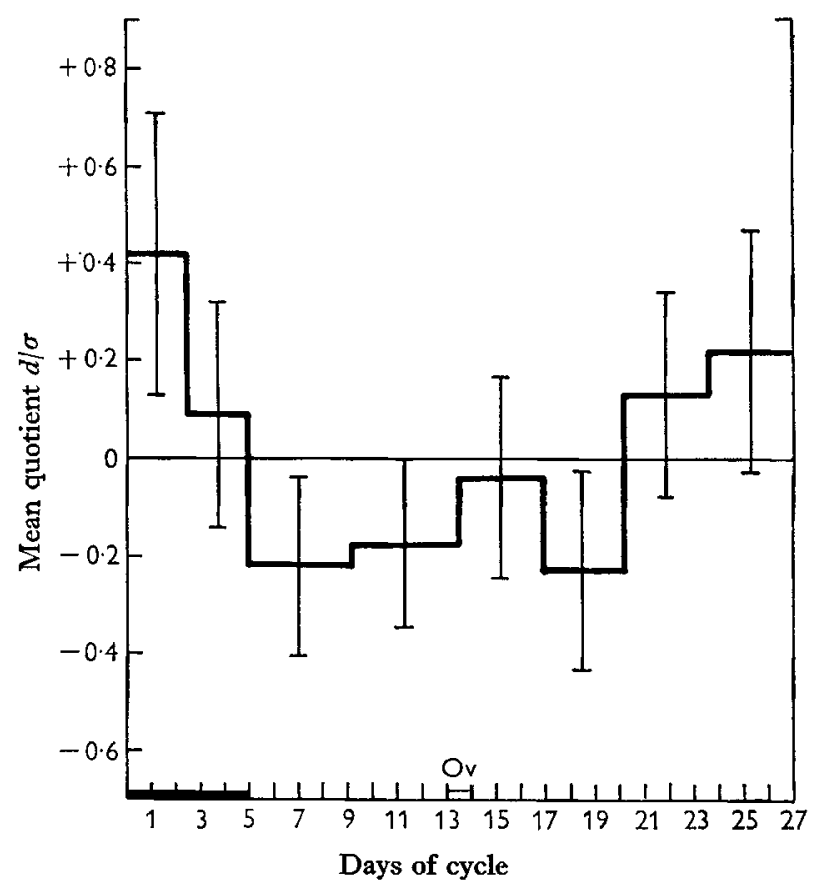

Fig. I. Mean quotient $d / \sigma$ for each of the eight parts of the menstrual cycle of twenty-eight young women (where $d$ is the average deviation of the body-weight for each part of the cycle from the mean body-weight for that cycle, and $\sigma$ is the standard deviation). Range of $d / \sigma \pm 2 \mathrm{SE}$ is shown by vertical lines. Occurrence of menstruation (__ ) and of ovulation ( $\mathrm{Ov})$ is shown on the abscissa.

\section{Distribution of deviations of more than $0.5 \mathrm{~kg}$ from mean body-weight}

An analysis was made to determine the magnitude of the maximum deviations and the frequencies with which these occurred in the different parts of the menstrual cycle. Deviations greater than $\pm 0.5 \mathrm{~kg}$ were referred to as 'significant deviations'. The maximum deviation from the mean body-weight was recorded for each part of the forty-eight cycles. There were forty-eight values for each part and these were divided into:

(a) those that showed a significant positive deviation (of $0.5 \mathrm{~kg}$ or more),

(b) those that showed a significant negative deviation (of $0.5 \mathrm{~kg}$ or more),

(c) those that showed a deviation within the range of $\pm 0.5 \mathrm{~kg}$.

These findings are given in Table 2 along with the numerical values of the greatest 
Table 2. Incidence of maximum deviations of greater than $\pm 0.5 \mathrm{~kg}$ from the mean body-weight in the menstrual cycle of twenty-eight young women

\begin{tabular}{|c|c|c|c|c|c|c|}
\hline \multirow[b]{2}{*}{$\begin{array}{l}\text { Part of } \\
\text { cycle }\end{array}$} & \multirow[b]{2}{*}{ Time of cycle } & \multicolumn{2}{|c|}{$\begin{array}{l}\text { Positive deviation } \\
\text { in weight }\end{array}$} & \multicolumn{2}{|c|}{$\begin{array}{l}\text { Negative deviation } \\
\text { in weight }\end{array}$} & $\begin{array}{r}\text { signi } \\
\text { devi }\end{array}$ \\
\hline & & $\begin{array}{l}\text { No. of } \\
\text { cycles }\end{array}$ & $\begin{array}{r}\text { Greatest } \\
\text { deviation }\end{array}$ & $\begin{array}{l}\text { No. of } \\
\text { cycles }\end{array}$ & $\begin{array}{r}\begin{array}{c}\text { Greatest } \\
\text { deviation }\end{array} \\
\text { devitat }\end{array}$ & cy \\
\hline $\begin{array}{l}\mathbf{I} \\
2\end{array}$ & $\begin{array}{l}\text { Menstrual phase: } \\
\text { First half } \\
\text { Second half }\end{array}$ & $\begin{array}{l}20 \\
13\end{array}$ & $\begin{array}{l}+r \cdot 55 \\
+0.90\end{array}$ & $\begin{array}{l}7 \\
6\end{array}$ & $\begin{array}{l}-0.87 \\
-1 \cdot 06\end{array}$ & \\
\hline $\begin{array}{l}3 \\
4\end{array}$ & $\begin{array}{l}\text { Postmenstrual phase: } \\
\text { First half } \\
\text { Second half }\end{array}$ & $\begin{array}{r}9 \\
12\end{array}$ & $\begin{array}{l}+I \cdot I 6 \\
+I \cdot 60\end{array}$ & $\begin{array}{l}\text { I6 } \\
\text { II }\end{array}$ & $\begin{array}{l}-1 \cdot 32 \\
-1.23\end{array}$ & \\
\hline $\begin{array}{l}5 \\
6 \\
7 \\
8\end{array}$ & $\begin{array}{l}\text { Postovulatory phase: } \\
\text { First quarter } \\
\text { Second quarter } \\
\text { Third quarter } \\
\text { Fourth quarter }\end{array}$ & $\begin{array}{r}9 \\
7 \\
\text { I0 } \\
\text { I3 }\end{array}$ & $\begin{array}{l}+0.96 \\
+0.87 \\
+x \cdot 77 \\
+I \cdot 25\end{array}$ & $\begin{array}{r}8 \\
15 \\
9 \\
9\end{array}$ & $\begin{array}{l}-0.95 \\
-1.25 \\
-0.94 \\
-0.90\end{array}$ & \\
\hline
\end{tabular}

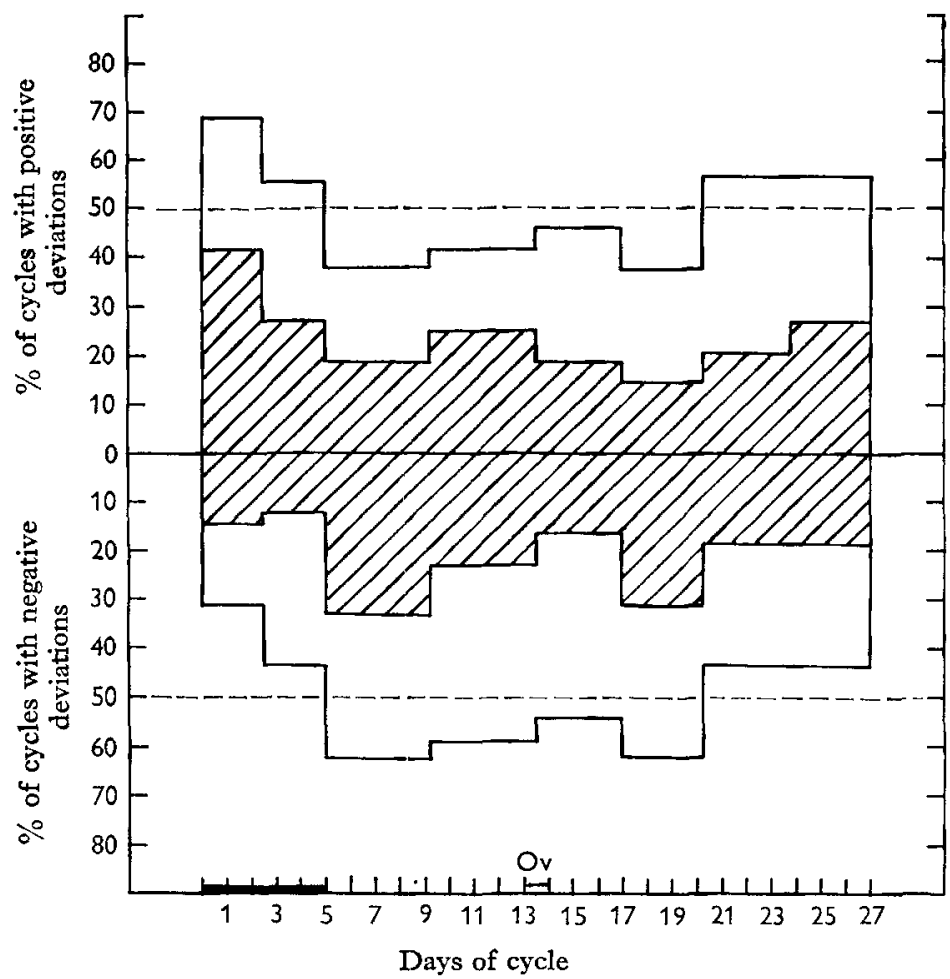

Fig. 2. Distribution of maximum deviations from mean body-weight of twenty-eight young women for the eight parts of forty-eight completed menstrual cycles (see p. 240). Percentage of cycles with significant positive or negative deviations (outside range $\pm 0.5 \mathrm{~kg}$ ) is denoted by the hatched areas; that with minor deviations (within range $\pm 0.5 \mathrm{~kg}$ ) by the clear areas. Occurrence of menstruation (__) and of ovulation (Ov) is shown on the abscissa. 
positive and negative deviation for each part of the cycle. The percentages of the cycles with significant positive and negative deviations are illustrated in Fig. 2. The minor (i.e. not significant) deviations in weight, which fell within the range of $\pm 0.5 \mathrm{~kg}$, have been divided into those that were positive and those that were negative, and these have been included in Fig. 2.

Just over half of the deviations lay between $\pm 0.5 \mathrm{~kg}$ and were fairly evenly distributed over the eight parts of the cycle (Table 2). Twenty cycles showed significant positive deviations during the first half of menstruation, compared with only seven negative deviations; this preponderance of significant positive deviations was reflected in the minor deviations with a greater percentage of positive than negative deviations (Fig. 2). On the other hand, there were more significant negative deviations than positive deviations during the first half of the postmenstrual phase; again the difference was reflected in the minor deviations.

The greatest positive deviation $(\mathrm{r} \cdot 77 \mathrm{~kg})$ occurred in the third quarter of the postovulatory phase, and the greatest negative deviation $(\mathrm{r} \cdot 32 \mathrm{~kg})$ in the first half of the postmenstrual phase (Table 2).

Horizontal lines at $50 \%$ for both types of deviations (Fig. 2) help to demonstrate the greater number of negative deviations during the postmenstrual phase and the first half of the postovulatory phase, also the greater number of positive deviations during the premenstrual and menstrual phases. Indeed, during the first half of the menstrual bleeding almost $70 \%$ of the deviations were positive.

The identical contours of the total (significant and minor) positive deviations and of the total negative deviations were similar to the contour of $d / \sigma$ illustrated in Fig. I. Hence a consideration either of the occurrence within the menstrual cycle of the maximum deviations of body-weight, or of the quotient $d / \sigma$ (in which the effects of the larger deviations have been greatly reduced) leads to the same conclusion with regard to change during the cycle.

\section{Comparison of two or more consecutive cycles of the same subject}

A true comparison between consecutive cycles of the same subject can be made only when the results have been obtained under similar conditions. Although the winter term was slightly shorter than the autumn term, it was a more suitable time for this study. Outside conditions were uniform in the winter season, and the subjects lived in a centrally heated building. Moreover, the students had settled down to a fairly fixed pattern of lectures, practical classes and study, with sport for some each Saturday and social activities mainly in the weekends.

The cycles of the eighteen subjects who had two or more cycles have been compared in Table 3; A refers to the first cycle observed, $\mathrm{B}$ to the second, and $\mathrm{C}$ to the third. The individual weight graphs were inspected to see which cycles revealed the features that had been found in the previous general analysis of the body-weights. The findings are recorded in the first three columns of Table 3 . Only four subjects $(\mathrm{I}, 9, \mathrm{I} 4,24)$ showed similar features in their two cycles; the profiles of their bodyweight graphs were also similar on inspection but were by no means identical.

Only in subject 19 were two cycles of equal length; in eight more subjects the cycle 

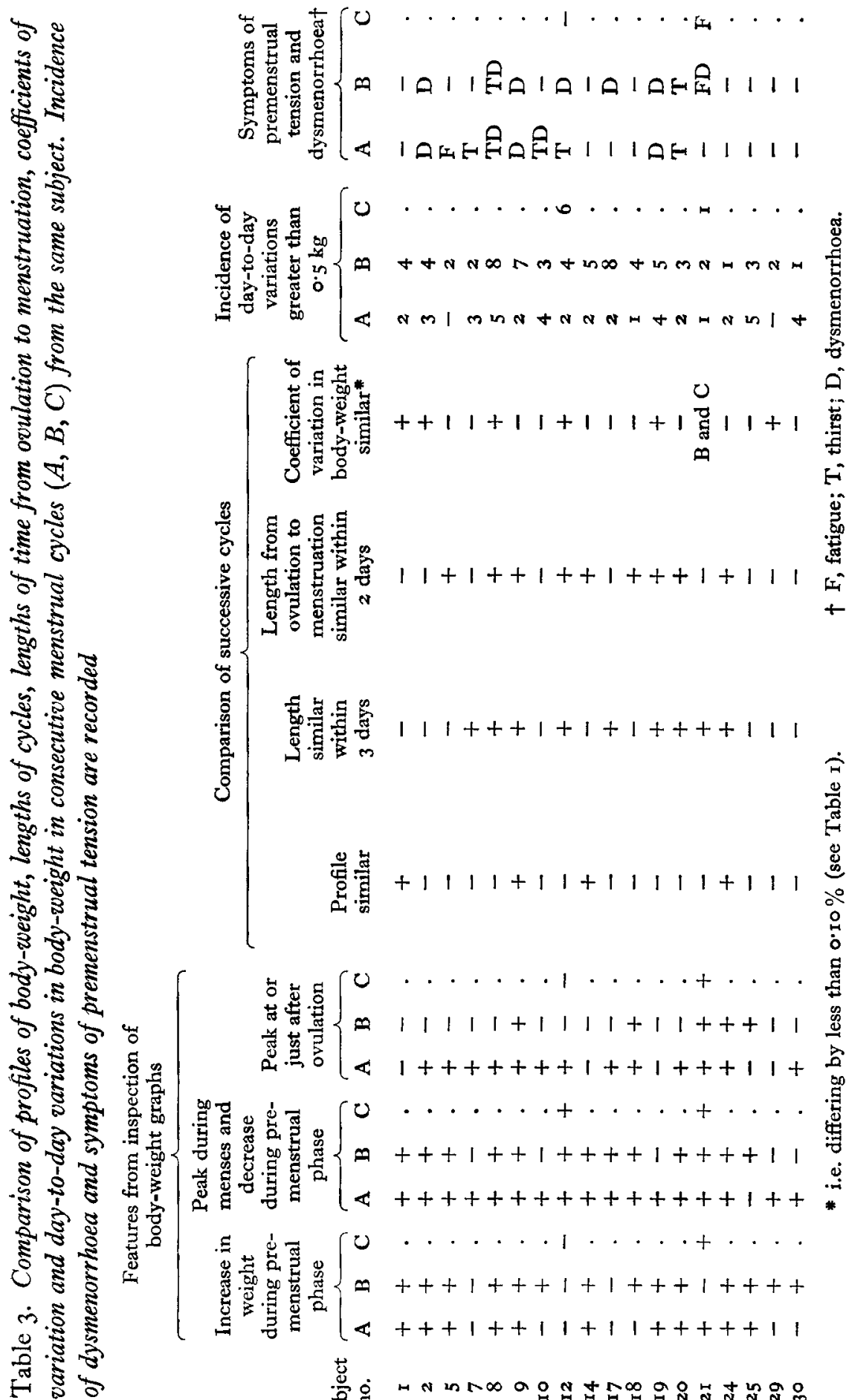
lengths were similar, i.e. within a range of 3 days. Ovulation took place a similar length of time before the next menstrual flow (i.e. within a range of 2 days) in nine subjects, of whom six had cycles of similar length. Similar coefficients of variation in body-weight (i.e. differing by less than $0 \cdot 10 \%$ ) were found for the two cycles of seven subjects.

Comparison of columns $4,5,6,7$ in Table 3 shows that no subject in this study had two cycles which were similar in the terms indicated. Subjects 9 and 24 had cycles of similar profile, length, and length of time from ovulation to menstruation, but their coefficients of variation in body-weight differed by 0.23 and $0.29 \%$, respectively. Three other subjects $(8,12,19)$ had cycles of similar length, length of time from ovulation to menstruation and coefficients of variation of body-weight, but the profiles of their weight graphs were dissimilar.

A lack of uniformity in weight profiles and coefficients of variation could be due to irregularities in bowel activity (subject 25) or in eating habits (subject 17 ) or to other possible causes which overshadowed the cyclic pattern in body-weight. Information on the possible causes of irregularity in weight profile may be obtained from the incidence of day-to-day variations greater than $0.5 \mathrm{~kg}$ listed in column 8 of Table 3 .

\section{Premenstrual tension}

Premenstrual tension is a term used to cover a variety of mental and physical symptoms occurring before the onset of menstruation (Israel, 1960; Bruce \& Russell, 1962). At the beginning of the study, the students were asked to report any symptoms experienced by them during the study, but those associated with premenstrual tension were never mentioned to them. The information was analysed, and the presence or absence of symptoms of premenstrual tension and of dysmenorrhoea was noted. This part of the study was in no wise emphasized to the students, and no student suffered severely from any of the symptoms. Seven of the twenty-eight subjects experienced both types of symptoms in cycle $A$, five reported only dysmenorrhoea and six premenstrual tension, leaving nine subjects without any symptoms. Ten of the eighteen with two or more cycles recorded no symptoms in cycle $B$, of which seven had already experienced none in cycle $A$; the symptoms of five of the eight students were similar in both cycle $A$ and cycle B (Table 3 ).

\section{DISCUSSION}

\section{Analysis of body-weight records}

Many methods have been used for analysing and interpreting body-weight records, but as yet no entirely satisfactory method has emerged that takes into account the overall body-weight trends, the variations in the duration of the menses, of the menstrual cycle, and in the time of ovulation. Some workers simply calculated the percentage of subjects whose individual weights showed a premenstrual gain (Okey \& Stewart, 1932-3; Sweeney, 1934; Morton, 1950). Thorn et al. (1938) were the first to attempt any type of comparative analysis in which the weights in all the cycles were considered together. They divided the cycles into premenstrual ( $7^{-10}$ days), men- 
strual, postmenstrual (3-5 days) and intermenstrual phases, and noted theoccurrence of sustained or temporary gains or losses of I kg or more; they did not regard changes of less than $\mathrm{I} \mathrm{kg}$ as significant. Klein \& Carey (1957) divided the cycle into four equal parts and compared the mean weight in each part with that in the other three parts. Chesley \& Hellman (1957) adjusted all the cycles to 28 days. Had their method been applied in this study, the time about ovulation in the short cycles would have been divided into two parts, separated by a gap of several days. In the long cycles, ovulation might have been omitted altogether. These workers derived $d / \sigma$ (Danforth $e t$ al. 1946) for each of the 28 days; they also noted the occurrence of maximal weights, and of maximal gains and losses when the cycles were divided in various ways after the manner of Thorn et al. (1938).

In all these methods of analysis the onset of menstruation was fixed, but the end of menstrual bleeding and the time of ovulation must have been reached over a considerable range of days. In our study, each cycle was divided into eight parts, using the beginning and end of menstruation and the time of ovulation as dividing lines. Hence the changes associated with the menstrual phase, the postmenstrual phase, and the postovulatory phase (of which the latter half was taken as the premenstrual phase) could be considered separately in the forty-eight cycles.

In their study of premenstrual tension, Bruce \& Russell (1962) corrected for the 'persisting tendency' of some of their subjects to lose or gain weight, in order that the steady trends might not obscure possible cyclic variations.

\section{Changes in body-weight with menstrual cycle}

The subjects were healthy women students of similar age ( $18-20$ years) and occupation, living in the same residence. They were therefore a more homogeneous group than had been studied by Thorn et al. (1938), by Thomas (1953), by Chesley \& Hellman (1957) or by Bruce \& Russell (1962). They were unselected as far as concerns awareness of premenstrual symptoms, and this, besides their youth, may explain why they showed a lower incidence of premenstrual symptoms than, for example, the subjects of Bruce \& Russell (1962) who were specially selected as sufferers and those of Thomas (1953) who were invited to complain of premenstrual symptoms.

The deviation in weight revealed by this study appeared to be greatest during the first half of menstrual bleeding rather than, as others had found, during the latter part of the premenstrual phase. Almost half of the subjects of Thorn et al. (1938) had gained I kg during the premenstrual phase which was lost during menstruation. No such clear-cut picture was obtained by Chesley \& Hellman (1957); one-third of their subjects showed a maximal weight gain during the last 8 days of the premenstrual period, which they suggested might have 'arisen by chance'. They also commented upon the disagreement about the exact time relations of the gain in weight with menstruation. The weight graphs recorded by Thomas (1953) demonstrated individual variations in the incidence of peaks in weight, which occurred just before, coincident with or just after bleeding. This was also found in the weight graphs in our study, but the peaks seemed to occur more frequently during the first few days of menstruation. 
This may be seen from Table 3 which summarizes the features of the body-weight graphs for subjects with two or more cycles. Thirty-two of the thirty-eight cycles showed a peak during menstruation followed by a decrease during the postmenstrual phase. Moreover, the highest number of maximum deviations ( $70 \%$ of the total) were positive during the first half of menstruation.

Although Chesley \& Hellman (1957) suggested that in their study the gain in weight during the premenstrual phase could have been expected by chance, they did mention that, although the curve joining the values for $d / \sigma$ showed no progressive trend in weight, it lay below zero for the first Io days and above zero for the final 9-10 days of the cycle. The highest point (equivalent to $0.25 \mathrm{lb}$ or one-quarter of a standard deviation from the mean) was reached on the gth or roth day before the next period; thereafter the curve was more or less a plateau until menstruation. Values for $d / \sigma$ in our study are not strictly comparable with those of Chesley \& Hellman (1957), since our values were not for separate days but were averaged for parts of the cycle. A somewhat different pattern emerged with the highest value $(+0.42)$ during the first half of menstruation. The quotient $d / \sigma$ fell below zero during the beginning of the postmenstrual phase, and remained there until the last half of the postovulatory phase, when it rose steadily above zero, reaching $0 \cdot 22$, the average for the last $3^{-4}$ days of the premenstrual phase (Fig. I).

\section{Influence of ovulation}

In most studies, gains in weight were recorded during the intermenstrual period and were attributed to ovulation. Chesley \& Hellman (1957) analysed the body-weights of fifteen cycles of seven nurses, the time of ovulation being deduced from their basal body temperatures. They found that the mean quotient $d / \sigma$ increased at about the same time as ovulation had occurred, the greatest average increase being one-third of the standard deviation. They summarized their findings by stating that the subjects studied did not show a significant weight change at the time of ovulation. However, Bruce \& Russell (1962) have since found a weight peak in seven of eleven cycles at ovulation deduced from basal rectal temperatures. In our study, the graph of $d / \sigma$ showed a small peak immediately after ovulation; this had also been found in the analysis of the day-to-day fluctuations in body-weight (Fig. 3, Robinson \& Watson, 1965). Since basal temperatures may not be a reliable indicator of ovulation, care must be used in interpreting any results about this time. Nevertheless, the findings suggest that some minor change in weight occurred at the time of ovulation, possibly after ovulation had taken place.

\section{Successive cycles in the same subject}

Eighteen of the twenty-eight subjects completed two or more cycles. Two cycles were also completed by the subjects of Chesley \& Hellman (1957), who stated that no subject showing a premenstrual gain in one cycle duplicated this pattern in her other cycle studied. These subjects were weighed on arrival at work, and thus the procedure could not be so carefully controlled as was possible in this study. Four of our subjects 
showed a similar profile of weight trend in successive cycles, but not one of these subjects had cycles similar in length, length of time from ovulation until the next menses, coefficient of variation in body-weight or incidence of the larger day-to-day variations (Table 3 ). The magnitudes of the day-to-day fluctuations and the frequency with which they occur influence directly the profile of the weight graph and the coefficient of variation in body-weight, with the result that an underlying trend may be overshadowed. Taggart (I962), in her careful investigation of a single subject, had found no changes of body-weight, food intake, water intake or urinary output which could be related to the menstrual cycle; she commented that this did not imply that such changes were completely absent but rather that if any cyclical variations were present they were completely masked by variations from other causes. It may be that in analysing all the results from all the forty-eight cycles together, the individual dayto-day fluctuations from causes other than menstruation cancelled each other out, so that the average trend of body-weight with the menstrual cycle emerged. Certainly the graphs of the quotient $d / \sigma$ (Fig. I) and of the distribution of maximum deviations (Fig. 2) are similar to that derived from all the day-to-day fluctuations (Robinson \& Watson, 1965, Fig. 2).

\section{General conclusions}

The foregoing analysis points to two major conclusions. First, when a sufficient number of cycles was analysed to smooth out random changes and to eliminate the variations in length and overall body-weight trends, a cyclic pattern was revealed. This suggests that there is an underlying periodic variation in body-weight but that this is so small that it may often be overshadowed in individual subjects. Second, even in a remarkably homogeneous and well-controlled group, there was a striking variation between cycles as to length and pattern of body-weight changes. Even successive cycles in the same individual often showed considerable differences. This variability, together with dependence upon extraneous factors, may go far to explain the conflicting reports in the literature.

\section{SUMMARY}

I. Daily weights were followed for 68 days in twenty-eight young women (aged 1 8-20 years) living and eating in the same residential hall and attending similar courses at the university. Two subjects completed three menstrual cycles, sixteen subjects completed two cycles, and ten subjects only one cycle, making a total of forty-eight cycles.

2. Some subjects tended to lose or gain weight, and the appropriate corrections were made in the records of their body-weight.

3. For comparison the cycles were divided into eight parts, using the beginning and end of menstruation, and the time of ovulation as dividing lines: first and second half of menstruation, the first and second half of postmenstrual phase (including the day of ovulation), and the four quarters of the postovulatory phase.

4. A distinct pattern of the average change in body-weight was obtained by two separate methods of analysis. The body-weight increased steadily during the latter half of the postovulatory phase (the premenstrual phase), reaching its highest value 
during the first half of menstruation. Thereafter the weight fell rapidly to low values during the postmenstrual phase.

5. Ovulation appeared to be associated with a minor peak in weight just after ovulation had taken place.

6. The findings from the analysis of the completed cycles were similar to those obtained previously from the analysis of the day-to-day fluctuations in body-weight.

7. Comparison of two or more cycles from the same subject demonstrated that no two cycles were similar in all respects, although they might agree in some of them, such as length of cycle, length of time from ovulation until the next menstrual flow, coefficient of variation in body-weight, incidence of day-to-day variation greater than $0.5 \mathrm{~kg}$, and profile of graphs of body-weight.

We wish to thank the subjects, without whose friendly co-operation this study would have been impossible. We are indebted to Dr G. F. S. Spears, Statistician, Department of Preventive and Social Medicine, University of Otago Medical School, for his advice on the statistical interpretation of the results, and for the compensating corrections required in the records of those subjects who gained or lost weight; and to Professor J. R. Robinson, Department of Physiology, for his helpful suggestions and interest in this study.

\section{REFERENCES}

Bickers, W. \& Woods, M. (I95 I). New Engl. F. Med. 245, 453.

Bruce, J. \& Russell, G. F. M. (1962). Lancet, ii, 267.

Chesley, L. C. \& Hellman, L. M. (1957). Amer. F. Obstet. Gynec. 74, 582.

Danforth, D. N., Boyer, P. K. \& Graff, S. (1946). Endocrinology, 39, 188.

Fortin, J. N., Whittkower, E. D. \& Kalz, F. (1958). Canad. med. Ass. F. 79, 978.

Israel, S. L. (1960). In Edema-Mechanisms and Management, p. 444. [J. H. Moyer and M. Fuchs, editors.] London: W. B. Saunders Co.

Khosla, T. \& Billewicz, W. Z. (1964). Brit. F. Nutr. 18, 227.

Klein, L. \& Carey, J. (1957). Amer. F. Obstet. Gynec. 74, 956.

Morton, J. H. (1950). Amer. F. Obstet. Gynec. 60, 343.

Okey, R. \& Stewart, D. (1932-3). F. biol. Chem. 99, 7 I 7.

Robinson, M. F. \& Watson, P. E. (1965). Brit. F. Nutr. 19, 225.

Sweeney, J. S. (1934). F. Amer. med. Ass. ro3, 234.

Taggart, N. (1962). Brit. F. Nutr. 16, 223.

Thomas, C. B. (1953). Ann. intern. Med. 39, 289.

Thomas, W. A. (1933). F. Amer. med. Ass. ror, I 126.

Thorn, G. W., Nelson, K. R. \& Thorn, D. W. (1938). Endocrinology, 22, I 55. 